\title{
Predictors of Success for African Black Physiotherapy Students in South Africa
}

\begin{abstract}
High school performance and aptitude tests are usually used to predict success at university, but this may not be applicable when the ethnic group of the student is considered. The aim of this study was to investigate factors that predict success of African black students in physiotherapy programmes and whether these factors are influenced by race. A mixed methods approach was used. One hundred and twenty eight graduates who graduated between 2000 and 2005 from eight universities in South Africa and six Heads of Physiotherapy Departments participated in the research. A postal questionnaire comprising closed and open-ended questions was used for graduate and in-depth interviews were conducted with Heads of Departments. Quantitative data were analyzed using descriptive analysis as well as inferential statistics using Chi square tests and logistic regression. Qualitative data was analysed using content analysis. Of the participants, $59 \%$ of the African black students were successful compared to $90 \%$ of the

\author{
Mbambo-Kekana N, PhD' \\ Rothberg A, PhD, MBBCh ${ }^{2}$ \\ Bruce J, $\mathrm{PhD}^{3}$
}

Musenge U, MSc Biostatistics ${ }^{4}$

1 School of Health Sciences, Faculty of Health Sciences, University of Limpopo

2,3,4 Physiotherapy Department, Faculty of Health Sciences University of the Witwatersrand white students. A significant association was found between race and success with factors such as sharing a residence room, obtaining information about university support systems from classmates, feeling part of the group of classmates and choosing physiotherapy as the first choice of career being predictors of success. Students also highlighted determination to succeed and become a physiotherapist, financial and family support, and a favourable learning environment to contribute to success. HOD interviews associated adequate knowledge about the physiotherapy profession, proficiency in the language of instruction, academic discipline, relevant support and integration in the class with success. It is recommended that matriculation results should not be the only predictors of success but tertiary institutions should consider broader factors such as residential accommodation and a supportive learning environment.
\end{abstract}

KEY WORDS: SUCCESS, PREDICTORS, PHYSIOTHERAPY, AFRICAN STUDENTS.

\section{INTRODUCTION}

The South African National Plan on Higher Education (NPHE) is based on the policy framework and the goals, values and principles outlined in the Education White Paper (1997). The intention was to develop a higher education system that would, amongst other things, promote equity of access and fair chances of success to all who are seeking to realize their potential through higher education, while eradicating all forms of unfair discrimination and advancing redress for past inequalities (White Paper 1997: 1.14). Two concerns have been raised by Griesel (2003) regarding higher education and African Black students. The author highlighted that African Black students tend to remain clustered in the humanities, with low enrolments in science, engineering and technology, business/commerce, and postgraduate programmes. Secondly, even though matriculation pass rates have improved in recent years, the throughput in higher education remains low. Given the vast disparities in provision and resources, the concern is that academic success or failure may reflect socio-economic inequalities and the legacy of apartheid rather than individual learners' intellectual ability or potential.

Physiotherapy remains one of the programmes with low admission and throughput rates for African black students in South Africa. There are currently eight universities in four provinces that offer physiotherapy training. The 2006 records (Department of Health) showed that there was a total intake of 311 first year physiotherapy students at seven universities of which 75 (24\%) were African black students. Thirty-one (41\%) of these students were admitted to one university and the remaining $39 \%$ were distributed among the other seven universities. In an effort to increase the number of black students, selection usually involved admission of students whose inferior education in racially segregated secondary schools resulted in poorer matriculation grades. Some, if not all the physiotherapy departments used additional criteria such as involvement in sports, leadership qualities, community involvement, with added points for originating from designated communities, to widen access to a diversity of students (Health Professions Council of South Africa (HPCSA) annual report, 2006) To date no studies specific to African students have been

Corresponding Author:

Dr N Mbambo-Kekana

School of Health Sciences,

Faculty of Health Sciences,

University of Limpopo

South Africa

Email: NoncebaMbambo-Kekana@ul.ac.za 
done to establish the impact of these criteria on student success.

Poor racial representation may not only be linked to admission concerns but also to underperformance at matriculation level (McKenzie and Clayton 1994). However, Badenhorst et al (1990) pointed out various detrimental non-academic experiences of black students, particularly at predominantly white universities, which include subtle racism, feelings of alienation, socio-political influences and concrete problems regarding finances. The change from school to university is also a major challenge because it is a life transition to which many students have considerable difficulty adjusting. In the South African context, most African black students with inferior educational and disadvantaged socioeconomic backgrounds are particularly vulnerable during this transition.

The present study took cognisance of the fact that with changes in the South African economic landscape and political dispensation, some black students are benefiting in the sense of economic empowerment of parents and therefore opportunities to attend well resourced schools or any school of choice without limitations, whilst some white students are may be less privileged than before with some decrease in financial support. It may well be that it is not only black students that are faced with challenges. For instance, there are white students who come from Afrikaans language high schools who attend English medium universities and vice versa, some of them also originate far from the universities where they study. These students are expected to cope with academic, social and emotional demands because they are supposedly from privileged backgrounds while more attention and deliberate effort of support is provided to black students. This study therefore set out to establish factors that could predict, or are associated with, academic success in a physiotherapy programme. It also attempted to establish whether those factors would be applicable to both African black and white students.

\section{METHODOLOGY}

A mixed method approach (Creswell, 2003) was adopted for this study. One- hundred-twenty-eight physiotherapists (66 black and 62 white) of the 310 who graduated between 2000 and 2005 from the eight universities and six Heads of Physiotherapy Departments participated in the research. For the purposes of this study, graduates who completed the degree in four years or four and a half years were defined as successful, and those that completed in five years and more were defined as unsuccessful. It was not possible to trace students who had left the physiotherapy programmes prior to graduation. A total of 310 questionnaires were distributed to the graduates through mail, fax, e-mail and hand delivery and 135 (43.5\%) questionnaires were returned. Of the 135 questionnaires, six were discarded because they had more than one error, and one faxed questionnaire was illegible. The remaining 128 questionnaires (41\%) were analyzed. For a postal survey a return rate of about $40 \%$ is considered adequate (Hicks, 2004).

The physiotherapists responded to a self-designed questionnaire which had closed and open ended questions. The questionnaire was validated by six experts and then piloted for construct validity and reliability on 10 graduates of 1999. The independent variables that were investigated in the quantitative section of the questionnaire were race, gender, matriculation results for biology, physical science, mathematics and English, type of school, language of instruction at school, career choice, socioeconomic background and uni- versity experience. Data were analyzed using descriptive and inferential analysis. The qualitative section of the questionnaire enquired about perceived reasons for student success. Responses were analyzed using content analysis as described by Mayan (2002). Six HODs participated in face-to-face, in-depth interviews where a semi-structured interview schedule was used. The schedule included questions on student admissions, throughput, factors contributing to success, and available support systems. Data from HOD interviews were subjected to data-reducing procedures described by Tesch (1990). Ethical clearance for conducting the study was obtained from the Ethics Committee of the University of the Witwatersrand.

\section{RESULTS}

The findings showed that African black students took an average of 5 years to complete the degree. The HODs reported that it was the first two years of study that often had to be repeated. Altogether there were 56/62 (90\%) successful white respondents and 39/66 (59\%) black respondents. This difference was significant $\left(\mathrm{X}^{2}=16.29 ; \mathrm{p}<0.001\right)$, with odds ratios of 0.155 for black students and 6.461 for white students. There was no association between gender and success for either race. Most of the white respondents obtained $\mathrm{A}$ and $\mathrm{B}$ matriculation aggregate symbols (70$100 \%$ average), while black respondents achieved D and E symbols (40 - 55\% average). Figure 1 shows the com-

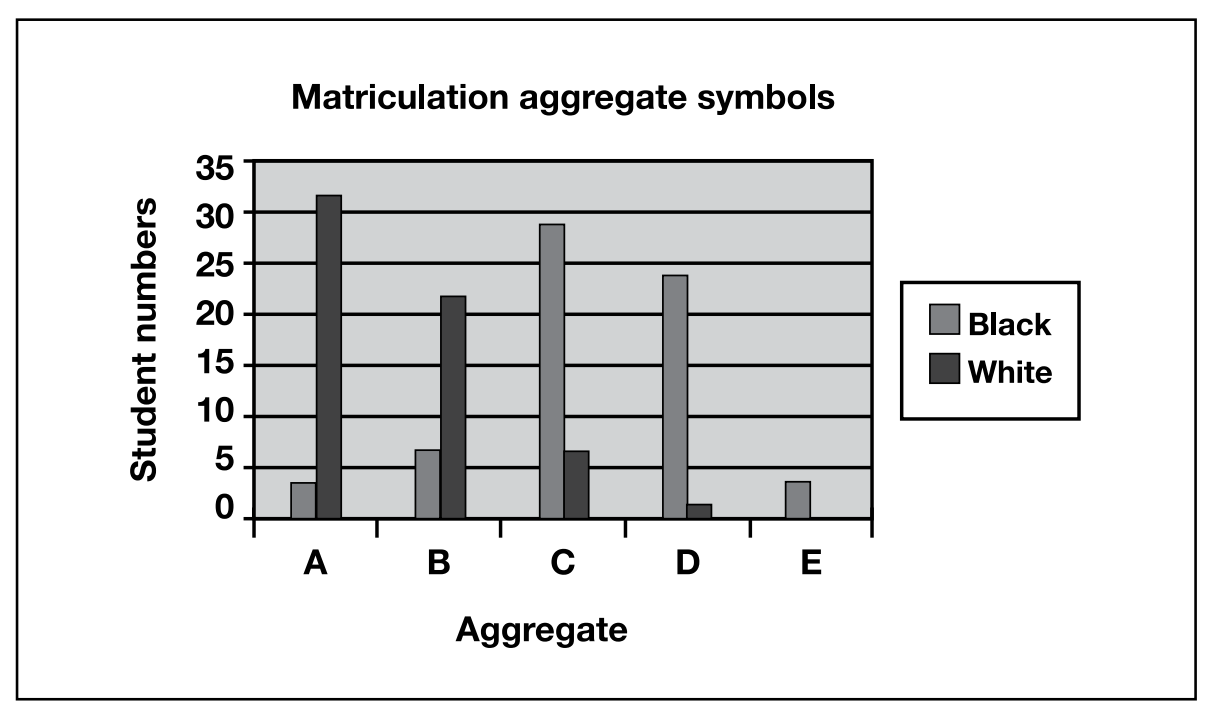

Figure 1: Matriculation aggregate symbols for black and white respondents 
parison between matriculation symbols obtained by black and white respondents respectively.

When considering the total group of black and white respondents, overall academic achievement, English and biology were found to be significant

\section{Table 1: High school performance and academic success in physiotherapy} ( $N=128)$

\begin{tabular}{|l|l|l|}
\hline Variable & $\mathbf{X}^{2}$ & $\mathbf{p}$ value \\
\hline Matric Aggregate & 18.85 & $<\mathbf{0 . 0 1}$ \\
\hline English & 15.73 & $<\mathbf{0 . 0 1}$ \\
\hline Biology & 12.19 & $\mathbf{0 . 0 3}$ \\
\hline Mathematics & 6.12 & 0.19 \\
\hline Physical Science & 9.88 & 0.07 \\
\hline
\end{tabular}

Table 2: Summary of Significant Variables for Black Respondents

\begin{tabular}{|l|l|l|}
\hline \multirow{2}{*}{ Category } & Variable & $\begin{array}{l}\mathbf{X}^{2} \\
\text { p value }\end{array}$ \\
\hline Career choice & Physiotherapy as a 1 ${ }^{\text {st }}$ choice of career & $\begin{array}{l}4.24 \\
0.03\end{array}$ \\
\hline \multirow{4}{*}{$\begin{array}{l}\text { University } \\
\text { experience }\end{array}$} & $\begin{array}{l}\text { Information about university support from } \\
\text { classmates }\end{array}$ & $\begin{array}{l}6.10 \\
0.01\end{array}$ \\
\cline { 2 - 3 } & Shared residence room & 4.51 \\
\cline { 2 - 3 } & University language of instruction & 0.03 \\
\cline { 2 - 3 } & Feeling part of the group & 6.51 \\
& & 0.04 \\
\hline
\end{tabular}

Table 3: Summary of all the Results

\begin{tabular}{|l|l|l|l|}
\hline \multirow{2}{*}{ Variable } & \multirow{2}{*}{ Quantitative } & \multicolumn{2}{l|}{ Qualitative } \\
\cline { 3 - 4 } $\begin{array}{l}\text { Support } \\
\text { - Shared residence room }\end{array}$ & & Graduates & HODs \\
- Received information & & & \\
$\quad \begin{array}{l}\text { about support systems } \\
\text { from classmates }\end{array}$ & $\checkmark$ & $\checkmark$ & $\checkmark$ \\
- Part of the group & $\checkmark$ & $\checkmark$ & $\checkmark$ \\
- Availability of support & $\checkmark$ & $\checkmark$ & $\checkmark$ \\
\hline Financial support & $\checkmark$ & $\checkmark$ & $\checkmark$ \\
\hline $\begin{array}{l}\text { Physiotherapy as a 1 } \\
\text { of career / knowledge of the } \\
\text { profession }\end{array}$ & - & $\checkmark$ & $\checkmark$ \\
\hline University language of instruction & $\checkmark$ & & \\
\hline Academic discipline & & & $\checkmark$ \\
\hline
\end{tabular}

study was to ascertain whether predictors of success were specific to one ethnic group, such an analysis proved to be impossible because of the small number of white respondents who were not successful (6). The following results therefore are a further exploration of the variables affecting success in the group of African black respondents.

The results showed that the spread of matriculation symbols were similar for successful and unsuccessful respondents. The point to note is that black students with D or E symbols which are regarded as low symbols, could be successful. The variables that were associated with success of black students are shown in Table 2 .

Logistic regression revealed that sharing a residence room $(\mathrm{OR}=3.09$; $\mathrm{p}=0.05$ ), obtaining information about university support systems from classmates $(\mathrm{OR}=6.25 ; \mathrm{p}<0.05)$, feeling part of the group of classmates $(\mathrm{OR}=3.23$; $\mathrm{p}<0.05)$ and choosing physiotherapy as the first choice of career $(\mathrm{OR}=.33$; $\mathrm{p}<0.05)$ were predictors of success of black students.

Although the above five variables were the most significant, together they account for only $18 \%$ of the variance, which means that $82 \%$ of the variance of success is not explained. Nevertheless, what is evident, from these results, is that they strongly identify support for the students and social integration during their years of studying, as important for success.

Themes that emerged with regards to student academic success suggest that, students who are determined to succeed and become physiotherapists, who have relevant support, and a favourable learning environment are more likely to be successful in their studies. Data obtained from the HOD interviews suggest that a successful student is one who enters physiotherapy training with relevant knowledge of the profession and of the challenges of university education, who has proficiency in the language of instruction, has relevant support, has academic discipline. and has become well integrated within the class and the department.

When all the quantitative and qualitative results are considered together 
there are overlaps. As shown in Table 3, these are between the quantitative and graduates' themes, between the quantitative results and HODs qualitative responses, and between the graduates' and HODs' themes.

\section{DISCUSSION}

The results of this study have shown that white respondents were more successful than black respondents, and that the average time taken to complete the degree for black respondents was 5 years. According to Graves (2008), in the USA the gap between black and white graduation rates also exists and many universities graduate black students at significantly lower rates than white students. In the South African context one reason for this outcome is that many black students are admitted with lower high school performance results in an attempt to increase access and correct the demographic imbalances. Taking the latter into account, this study has shown no statistical relationship between high school academic performance and success of black students in physiotherapy. Uncertainty about the validity of the matriculation mark as a predictor of further performance has long existed for low-scoring, disadvantaged students from the previous DET (Department of Education and Training) black-only educational systems (Herman, 1995; Yeld and Haeck, 1997). Herman (1995) questioned whether the matriculation examination is primarily a prognostic test to predict future academic success or whether it is an assessment of a standard of general education. Almost certainly, the latter is significant, but as shown in this study, candidates with poor educational background are capable of success and the challenge is to identify and nurture the relevant factors and/ or attributes.

Comments from the HODs indicate that black students tend to perform poorly academically during the first and second year of study, and some exit the programme at this level. In 1993, Tinto estimated that about $60 \%$ of all students who leave university do so during their freshman year. Lowe and Cook (2003) demonstrated that the transition from school to university can be a particularly difficult and unsettling experience for many students as they are entering an unfamiliar domain. It is at this time that students, regardless of their culture or educational background, are likely to encounter academic failure, and are most at risk with respect to a range of potential social, emotional, health and financial problems (McInnis, 2001).

The results also showed that $41 \%$ of black respondents had achieved only the lower range of high school symbols (D and E). Admission of students with D-E aggregate symbols raises questions concerning lower academic standards at the admitting universities. However, in South Africa there are quality assurance systems subscribed to by all academic physiotherapy departments. Firstly, all departments are subjected to a regular and standardized accreditation process by the Health Professional Council of South Africa. Secondly, all forms of each university's evaluation are subject to moderation by external examiners from the other universities. This suggests that the standard of training is the same throughout the country and some students are able to succeed with lower matriculation symbols. What then are the predictors of success?

From the analyses of the quantitative data in the present study, it was found that shared accommodation in a university residence, information from classmates, physiotherapy as first choice of career, university language of instruction and being part of the group predicted academic success. These are non-cognitive predictors and largely refer to support.

\section{Shared university residence room}

The fact that sharing a room at a university residence is a predictor of success suggests that having a roommate is a source of physical, social and academic support. Tinto (1993) observed that residence halls provide scaled down environments that enable newcomers to find an early physical, social and academic anchor during the transition to college life. Academic support from a roommate can be in the form of sharing academic problems as well as information regarding where assistance can be sought. Blimling and Hample (1979) found that students who live in campus residence halls with structured emphases upon studying improve their academic performance at university.

\section{Integration}

When students attend a university where they are a majority or where the culture of the university favours them, there is often greater cultural continuity between the home and university environment that provides them with a sense of familiarity, belonging and security. Sedlacek (1999) states that research on undergraduate black students in predominantly white universities in Tennessee showed that many had not achieved a feeling of belonging. The results from this study showed that African black respondents who felt that they were part of the group were more successful. Integration into the group of fellow students is important because physiotherapy training involves group work and is partnership orientated. When asked about factors that contributed to feeling part of the group, responses included forming good relationships, supporting one another, engaging in academic activities together, and small classes that encouraged closeness.

According to the HODs interviewed, some physiotherapy departments are already creating opportunities for students to socialize and feel part of the student community. Tinto's Student Integration Model (1975 and 1993) places a greater emphasis on the role of within-institution peer culture. Tinto (1993) also asserted that becoming integrated into the academic and social systems of a university requires students to navigate the stages of separation, transition, and incorporation. Separation involves disassociating from the norms of past communities. In transition, students find themselves having separated themselves from their past lives but having not yet adopted the norms and behaviors of their new environment. Incorporation and integration happens when students adapt to and adopt the prevailing norms and behavior patterns of their new community. The primary components of the process of incorpo- 
ration involve academic and social integration of students into the life of the university (Tinto, 1993).

\section{Obtaining information about support systems}

The graduates were asked how they found out about the support systems that were available at university and obtaining information from classmates was found to be a predictor of success. Harmon and King's (1985) expert systems theory suggests that successful college students are those who are 'experts' at being successful as students because they are able to obtain theoretical (book) and heuristic (campus) knowledge. Support systems at university form part of this heuristic knowledge and some students acquired it through classmates. Availability of support was a common theme mentioned by the HODs and graduates. The support proposed was financial as well as moral. Landsman (2000) highlighted that most black students are distracted from their studies by financial difficulties, which ranged from paying tuition fees to being able to afford to eat.

\section{Proficiency in language of instruction}

Another common qualitative theme was language proficiency as a predictor of success for African black students, although it was not found to be significant in the quantitative analysis. Almost all HODs that were interviewed indicated that black students proficient in English language were more confident and well integrated. Various universities have language support services for all students that need the service, however, very few respondents in the present study indicated that they made use of these services. Nolan (2002) indicated that most South African students do not think they have any problem with English, however, there are indications that their actual ability may be less than they perceived it to be (Buthelezi, 1995).

\section{Other contributing factors}

Prior knowledge of the physiotherapy profession was seen as a contributor to success and the HODs felt that if a student was determined to achieve a goal, they would put in the effort. Pintrich and Schunk (2002) define this as intrinsic motivation whereby an individual engages in an activity for its own sake and not as a means to an end. Fraser and Killen (2005) found that the 'success' items that both lecturers and students ranked highly paint a picture of a selfmotivated, hard-working student who can learn independently, prepare well for examinations and who has made a wise choice of course of study. Selecting physiotherapy as a first career choice was found to be a predictor of academic success as was prior knowledge of the profession.

Conditions under which students learn were mentioned as a factor that can influence students' academic performance. These conditions were related to sound family support, financial stability and strong support from the physiotherapy department. If the social circumstances of the student allow him/her to organize academic life properly, that student will stand a better chance of succeeding academically. Anecdotally, the authors are able to report that a common theme amongst the current students who have failed first and second year is the distance between the university and their homes and their inability to study as a result of leaving home at $5 \mathrm{am}$ and returning at $9 \mathrm{pm}$. This talks to accommodation at university as one of the predictors of success.

\section{CONCLUSION}

This study covered students who graduated between 2000 and 2005. Much has changed in South Africa since the turn of the century and more black students have access to educational systems that were previously difficult to enter. The consequence of this development is that more African black students will (eventually) matriculate with marks that are equal to those of their white counterparts. The first goal, at that point, would be to attract students with top matric marks into physiotherapy.

Until the equality in marks is attained, alternative selection criteria are being used and should be monitored on regular basis. The reality is that for some time there will still be African black students who obtain lower matriculation results but who have potential to succeed in physiotherapy programmes. Access without support presents only a limited opportunity (Engstrom and Tinto, 2008). With regard to these students the following goals should receive attention:

- Ensuring that they are applying on the basis of knowledge about the profession and the demands and expectations of higher education and university life. This implies effective marketing strategies

- On application, attempt to identify students with the desirable personal attributes (academic discipline, determination, ambition)

- Academic and non-academic criteria used by the different universities for selection should be continuously monitored for their value as predictors of success.

- On admission, integration into the student body should be promoted and transition from high school be managed by:

- $\quad$ Providing effective orientation programmes, including expectations of the university

- Offering shared accommodation for those in need, particularly first year students

- Providing social support at residences (and academic support where indicated)

- Most importantly, during the programme, identify students at risk and offer appropriate interventions.

On the basis of the study that was carried out, implementation of the above may facilitate learning and promote academic success of African black students. However, this should be formally measured and studied in order to support the hypothesis.

\section{Acknowledgements}

All the physiotherapists and physiotherapy Heads of Departments who participated in the study.

University of the Witwatersrand, National Research Foundation and the South African Society of Physiotherapy for funding. 


\section{REFERENCES}

Badenhorst FD, Foster DH, Lea SJ 1990. Factors affecting academic performance in firstyear psychology at the University of Cape Town. South African Journal of Higher Education. 4(1): 39-45.

Blimling GS, Hample D 1979. Structuring the peer environment residence halls to increase performance in average ability students. Journal of College Students Personnel. 20:311-316.

Buthelezi Q 1995. Black South African English. Language and Social History: Studies in South African Sociolinguistics. 242-250.

Creswell JW 2003. Research design: Qualitative, quantitative and mixed methods approaches. Thousand Oaks, CA: Sage Publications.

Department of Education 1997. Education White Paper 3. A programme for the Transformation of Higher Education, General Notice 1196 in the Government Gazette 18207 of 1997-08-15. Pretoria.

Department of Education 2001. National Plan for Higher Education. Pretoria: Department of Education.

Engestrom K, Tinto V 2008. Access without support is not opportunity. Change January/ February: 46-50.
Fraser W, Killen R 2005. The perceptions of students and lecturers of some factors influencing academic performance at two South African universities. Perspectives in Education. 23(1): 25-40.

Graves L 2008. The gap in graduation rates: at many colleges, a disparity in who makes it to a diploma. U.S. News and World Report. 144(13): 62-63.

Griesel H 2003. Controversies of access to Higher Education study - The changing FEHE interface. Annual AEAA Conference (SAUVCA), Cape Town.

Harmon P, King D 1985. Expert systems. New York: Wiley.

Health Professions Council of South Africa: Physiotherapy, Biokinetics and Podiatry Professional Board Education Reports of 2003 and 2004.

Herman HD 1995. School-leaving examinations, selection and equity in higher education in South Africa. Comparative Education. 31: 261-274.

Killen R, Fraser WJ 2002. Success and failure in tertiary studies: Perceptions of students and lecturers. Paper presented at the annual Conference of the South African Association of Educators, Pretoria.

Landsman CS 2000. Factors perceived by Black students as affecting their success or failure in the
Department o Psychology within the University of The Witwatersrand. A Research Report Submitted in Part Fulfillment of the Degree of Master of Arts by Coursework. University of the Witwatersrand.

Lowe H, Cook A 2003. Mind the gap: are students prepared for higher education? Journal for Further and Higher Education. 27(1): 53-76.

Mayan MJ 2002. An Introduction to Qualitative Methods: A Training Module for Students and Professionals. International Institute for Qualitative Methodology. Alberta, Canada.

McInnis C 2001. Researching the first year experience: where to from here? Higher Education Research and Development. 20(2): 105-114.

Nolan V 2002. Influence of attitude towards statistics, English language ability and mathematical ability in subject quantitative techniques at the Vaal Triangle Technikon, South Africa. Vaal Triangle Technicon.

Sedlacek WE 1999. Black students on white campuses: 20 years of research. Journal of College Student Development. 40: 538-549.

Tesch R 1990. Qualitative Research: Analysis Types and Software Tools. Bristol, PA: The Falmer Press.

Tinto V 1975. Dropout from higher education: A theoretical synthesis of recent research. Review of Educational Research. 45: 89-125. 